\title{
Common Core and the Continued Socioeconomic Achievement Gap: How Can We Better Prepare Future Teachers?
}

\author{
Lauren Dotson Davis ${ }^{1}$ \\ ${ }^{1}$ College of Education, Health, and Human Development, Montana State University, Bozeman, Montana, United \\ States \\ Correspondence: Lauren Dotson Davis, College of Education, Health, and Human Development, Montana State \\ University, Bozeman, Montana, United States. E-mail: lauren.davis6@montana.edu
}

Received: September 6, 2019 Accepted: October 5, 2019 Online Published: October 24, 2019

doi:10.5539/jel.v8n6p1 URL: https://doi.org/10.5539/jel.v8n6p1

\begin{abstract}
This paper discusses a longitudinal study of North Carolina middle level student proficiency levels on standardized assessments since the shift to the Common Core curriculum. Student poverty and its impact on student achievement the focus of this paper, and this study analyzes long-term proficiency trends and while delving into inequity implications regarding socioeconomic status. Recognizing the impact of poverty on student achievement as measured by standardized tests, the author questions the explicit practices of teacher preparation programs in preparing teacher candidates to work with students of poverty, specifically pertaining to the middle level student.
\end{abstract}

Keywords: middle level, assessment, poverty, teacher preparation

\section{Introduction}

\subsection{Standardized Testing and the Socioeconomic Achievement Gap}

Students today face a myriad of challenges unlike those that students in previous generations; while many of these challenges are beyond the control of the professional educator, there are areas in which teachers and administrators can increase their awareness and apply intervention strategies which may bring about positive change in students' lives. It is a well-known fact that students of lower socioeconomic status frequently exhibit an academic achievement gap on standardized testing; North Carolina has attempted to rectify this issue by implementing the Common Core curriculum standards in the hope that a rigorous national curriculum would serve as an "equalizer" for high poverty students and the related achievement disparity. While previous research evaluated the validity of this claim for middle level students during the initial implementation of Common Core in North Carolina (Dotson \& Foley, 2016), this study analyzed this issue from a longitudinal basis over the course of a full curriculum cycle (5 academic years) in this state, ending with analysis from testing data from the 2016-2017 academic year. The author analyzed middle level standardized assessment data, and for the purpose of this study, middle level is defined as grades 6-8 in North Carolina.

\subsection{Poverty and Educational Inequity}

In the United States, more than 15.5 million children are poverty-stricken according to the definition of poverty as a family of four living on less than $\$ 22,000$ annually, which translates to one in five American children (Achievement Gap, 2011; Brooks-Gunn \& Duncan, 1997). Poverty can also reference a lack of time, important relationships and models, proper nutrition, health, and sleep in addition to monetary resources (Pawloski, 2014). In this context, poverty will relate to a deficit in all of these areas, as well as a lack of equitable access to a high-quality education.

The recent downturn in our nation's economy has only resulted in a greater income and achievement gap between our schools' wealthy and disadvantaged children: “...the Great Recession wreaked havoc among working-class families' employment. This has led to greater residential segregation and homogeneously poor neighborhoods, leading to a higher concentration of poor students in certain schools" (Neuman, 2013, p. 18). Wealthier families spend nearly seven times more on their child's educational enrichment than low-income families, and only $36 \%$ of low-income parents read to their kindergarten-age children each day, compared with $62 \%$ of upper-income parents, resulting in 400 more hours in literacy activities than low-income students by the time they enter kindergarten 
(Jensen, 2009; Neuman, 2012; Tavernise, 2012). Moreover, children from low SES homes are statistically twice as likely to have learning-related difficulties in schools than children from more affluent homes (Brooks-Gunn \& Duncan, 1997; Morgan, Farkas, Hillemeier, \& Maczuga, 2009).

North Carolina follows very much in the same pattern; according to data from the National Equity Atlas, one in five children in North Carolina attend a high poverty school (classified as having $75 \%$ or more of its students receiving free or reduced lunch) (2018). Further, there is a large per-pupil spending disparity across counties in North Carolina, extending up to a $\$ 2,280$ difference (Kennedy, 2016). These discrepancies, along with the high proportion of students attending high poverty schools, unfortunately reflect the described national trends.

\subsection{Relevant Scholarship}

Sadly, empirical data shows that students from low-SES schools enter high school 3.3 grade levels behind students from higher SES schools. In addition, this same study illustrates that students from the low-SES groups learn at slower rates over 4 years than children from higher SES groups, graduating 4.3 grade levels behind those of higher SE groups based on achievement data from reading, mathematics, science, and social studies (Palardy, 2008, para. 15). Another recent study found that the gap between high SES and low SES students has grown more than $40 \%$ since the 1960s and is now more than twice the gap between Caucasian and African American students (Tavernise, 2012). Correlational studies also exhibit a strong relationship between high poverty and poor academic performance (Sirin, 2005; White, 1982; White et al., 1993). This correlation begins at the beginning of a child's academic career, and even before, in some cases. Additionally, a child's environment is said to effect $66 \%$ of a child's academic performance, while genetics only affects $34 \%$ of academic functioning (Pawloski, 2014). While varied on context, these data all point to one simple conclusion: high poverty students are set up to fail in our current educational system, and standardized assessments further drive this point home.

Standardized assessments are not always the "villain" in educational research; these tests can provide an indication of students' ability on a variety of topics while identifying areas of strengths and weaknesses, and they can also be a useful tool for assessing the schools themselves (Brown \& Hattie, 2012). Additionally, standardized assessments can provide students with an individualized report of where they stand academically and can serve as a benchmark while providing the opportunity for self-reflection and motivation for self-improvement. Currently, standardized assessments are mandated both by the state of North Carolina as well as federally to remain compliant with the reauthorization of the Department of Education's ESSA Act (Every Student Succeeds Act); however, in a system where the cards are stacked against low-income students, these tests are often the source of tremendous anxiety for both students and their teachers due to their high-stakes nature. Sadly, as a result of this, test anxiety is now a common ailment amongst students across the nation; because of anxiety-related nausea, the Stanford-9 standardized exam, for example, even comes with instructions as to what actions the test administrator must to take if a student vomits on a test booklet, according to the 2002 edition of the Sacramento Bee (Ohanian, 2002). Stories like this add to the public sentiment that these tests are inflicting serious harm to children today both academically and emotionally, and these assessments do not result in improved cognition (Horn, 2003; Popham, 2001). Further, researchers assert that high-stakes testing

"has several disadvantages including placing low SES schools in jeopardy of losing their accreditation, damaging the reputation of outstanding teachers, harming the self-image of those persons in communities with lower SES, and publicizing the looming threat of state takeover or privatization. [Researchers] believe the United States should establish legislation that takes the low SES diversity into account because while the test promotes accountability, it does not promote understanding or collegiality among teachers and administrators [in terms of sharing of resources, collaboration, etc.].... They also state that students from homes or neighborhoods of low SES tend to have less varied cultural or academic experiences, less support (financial, academic, technological) and encouragement from home, and less early childhood preparation than their counterparts from middle - or upper - class backgrounds....[and]research suggests that students with less economic support from home tend to achieve at or below grade level" (Baker, 2010, pp. 194-195).

It is also worth noting that testing data can paint an inaccurate picture regarding America's schools. U.S. Secretary of Education Arne Duncan warned in 2011 that unless specific changes are made to the Elementary and Secondary Education Act that as many as $82 \%$ of America's public schools could be labeled as failing (as cited in McNeil, 2011). These inaccuracies are further supported by Polikoff and Porter (2014). Polikoff and Porter evaluated standardized test scores of teachers who were considered high-quality based on feedback from student surveys and principal observations. In their quantitative analysis, they found little to no correlation between survey results that indicated excellent teaching according to student and principal feedback and standardized student test scores. Furthermore, this study determined that teachers only account for a maximum of $14 \%$ variance in student test 
scores, supporting the stance that environmental factors far outweigh teacher input when it comes to standardized test scores. Because of this recent study some educational associations, like the Houston Federation of Teachers, have filed federal lawsuits against using standardized assessments as evaluative instruments for teachers, arguing that this violates educators' rights.

While the previously outlined research asserted that teachers account for a small variance in student test scores, emphasizing the importance of external environmental factors in student achievement, there is also evidence that supports that access to high-quality teachers does make a difference in student achievement. Pawloski (2014) reported that one year with an effective teacher yields an additional \$50,000 of lifetime earnings per student, and 9 out of 10 students that move upward out of poverty state that it is because of an important student-teacher relationship they had as children. However, students in poverty are not always given the access to the strongest classroom teachers. Often, low socioeconomic schools are staffed by inexperienced teachers with less education and experience, and frequently these classrooms are coupled with a higher proportion of students with low academic skills (Baker, 2010). Because teachers are not prepared for these unique challenges, the turnover rate in high-poverty schools remains high, specifically in North Carolina; in the 2004-2005 academic year, high-poverty school district turnover rates ranged from a low of $12 \%$ to a high of $57 \%$, and these rates have only increased with budgets tightening after the Great Recession (Teacher Retention at Low-Performing Schools, 2006). Furthermore, many teacher preparation programs are considered a "one size fits all" approach to teaching practices, which does not adequately prepare teachers for what challenges they will face in a high poverty school setting (Pawloski, 2014).

\subsection{Purpose of Research}

While many studies and meta-analyses have been performed over the years to determine whether-and how-a relationship exists between socioeconomic status and student achievement, a longitudinal study has not yet been performed comparing socioeconomic status and student achievement with the new national Common Core curriculum; for this reason, it is a worthwhile venture to compare these test scores and students' socioeconomic status (Sirin, 2005; White, 1982; White, Reynolds, Thomas, \& Gitzlaff, 1993).

\section{Method}

The purpose of this study was to determine whether a significant difference exists in academic achievement when comparing by socioeconomic levels in the North Carolina middle grades learner as measured by end-of-grade standardized tests. This study was an analysis of data from two recent testing years after the change in cut scores and proficiency levels with North Carolina's Common Core Curriculum and updated curriculum and testing instruments in 2014, following the year of initial implementation in 2013; it also analyzed scores in 2017 with reference to economically disadvantaged students (which utilizes the most recent data available). This nonexperimental quantitative study with secondary data analysis was designed to determine how socioeconomic status and student achievement on high-stakes assessments were related. The study was focused on middle grades students in North Carolina public schools during the 2014 and 2017 end-of-grade state assessments, and only public schools configured in grades 6-8 that operate on a traditional school calendar were considered for this study.

\subsection{Variables, Data Sources, and Statistical Analyses}

In this study the socioeconomic status of the student, the academic year, and the grade of the student are the independent variables, and the dependent variable is academic achievement as indicated by proficiency levels (percentage of students labeled as proficient) on standardized assessments in the areas of reading and mathematics in the middle grades (grades 6-8). Socioeconomic status levels were determined by the percentage of student population within the middle school that received free or reduced cost lunch during that school year, which was reported to the North Carolina School Report Card website. Socioeconomic levels used for this study were divided into five levels as determined by the percentage of students receiving free or reduced price 1 unch: $1 \%-40 \%$ of students on free or reduced cost lunch, $41 \%-60 \%$ of students on free or reduced cost lunch, $61 \%-80 \%$ of students on free or reduced cost lunch, and $81 \%-100 \%$ of students on free or reduced cost lunch. I have combined levels $1 \%-20 \%$ and $21 \%-40 \%$ (the highest socioeconomic levels) because the population size was too small and therefore inadequate to be a representative sample.

Paired samples $\mathrm{t}$ tests were performed to determine whether significant differences exist between student achievement in each grade level, academic year, and tested subject area (mathematics and reading in 6th and 7th grades, and mathematics, reading, and science in 8th grade) based on various levels of socioeconomic status levels within the school. Minitab was used to analyze data, all of which were analyzed at the .05 level of significance. 
For this study, data were collected and analyzed from every school that concurrently houses grades 6-8 in North Carolina that also reported standardized achievement data on reading and mathematics as well as SES level of their school to the North Carolina Department of Public Instruction for the 2013-2014 and 2016-2017 academic years. These data were collected from North Carolina report cards from these years from the North Carolina Department of Public Instruction website. For schools to be reported on report cards, the school must have been operated for at least the previous 3 years as well as have reported complete information to the state of North Carolina. Schools that were ineligible to report information for the 2013-2014 and 2016-2017 school years were not included in this study. Additionally, private and charter schools were not included in this study, nor were schools with only one or two grade levels (i.e., schools organized as a 7-8 school or a sixth grade only school) considered for this study.

\subsection{Research Questions}

Research Question 1: Is there a significant difference in proficiency scores for economically disadvantaged middle level students in North Carolina schools with $1-40 \%$ poverty rates on the 2014 and 2017 standardized achievement tests?

HO1: There is no significant difference in proficiency scores for economically disadvantaged middle level students in North Carolina schools with $1-40 \%$ poverty rates on the 2014 and 2017 standardized achievement tests.

Research Question 2: Is there a significant difference in proficiency scores for economically disadvantaged middle level students in North Carolina schools with $41-60 \%$ poverty rates on the 2014 and 2017 standardized achievement tests?

HO2: There is no significant difference in proficiency scores for economically disadvantaged middle level students in North Carolina schools with $41-60 \%$ poverty rates on the 2014 and 2017 standardized achievement tests.

Research Question 3: Is there a significant difference in proficiency scores for economically disadvantaged middle level students in North Carolina schools with $61-80 \%$ poverty rates on the 2014 and 2017 standardized achievement tests?

HO3: There is no significant difference in proficiency scores for economically disadvantaged middle level students in North Carolina schools with 61-80\% poverty rates on the 2014 and 2017 standardized achievement tests.

Research Question 4: Is there a significant difference in proficiency scores for economically disadvantaged middle level students in North Carolina schools with $81-100 \%$ poverty rates on the 2014 and 2017 standardized achievement tests?

HO4: There is no significant difference in proficiency scores for economically disadvantaged middle level students in North Carolina schools with $81-100 \%$ poverty rates on the 2014 and 2017 standardized achievement tests.

Research Question 5: Is there a significant difference in proficiency scores for all middle level students in North Carolina schools with 1-40\% poverty rates on the 2014 and 2017 standardized achievement tests?

HO5: There is no significant difference in proficiency scores for all middle level students in North Carolina schools with $1-40 \%$ poverty rates on the 2014 and 2017 standardized achievement tests.

Research Question 6: Is there a significant difference in proficiency scores for all middle level students in North Carolina schools with $41-60 \%$ poverty rates on the 2014 and 2017 standardized achievement tests?

HO6: There is no significant difference in proficiency scores for all middle level students in North Carolina schools with $41-60 \%$ poverty rates on the 2014 and 2017 standardized achievement tests.

Research Question 7: Is there a significant difference in proficiency scores for all middle level students in North Carolina schools with $61-80 \%$ poverty rates on the 2014 and 2017 standardized achievement tests?

HO7: There is no significant difference in proficiency scores for all middle level students in North Carolina schools with $61-80 \%$ poverty rates on the 2014 and 2017 standardized achievement tests.

Research Question 8: Is there a significant difference in proficiency scores for all middle level students in North Carolina schools with $81-100 \%$ poverty rates on the 2014 and 2017 standardized achievement tests?

HO8: There is no significant difference in proficiency scores for all middle level students in North Carolina schools with $81-100 \%$ poverty rates on the 2014 and 2017 standardized achievement tests. 
Research Question 9: Is there a significant difference between proficiency levels for economically disadvantaged sixth grade students in both reading and math assessments on the 2014 and 2017 state report card?

HO9: There is no significant difference between proficiency levels for economically disadvantaged sixth grade students in both reading and math assessments on the 2014 and 2017 state report card.

Research Question 10: Is there a significant difference between proficiency levels for economically disadvantaged seventh grade students in both reading and math assessments on the 2014 and 2017 state report card?

HO10: There is no significant difference between proficiency levels for economically disadvantaged seventh grade students in both reading and math assessments on the 2014 and 2017 state report card.

Research Question 11: Is there a significant difference between proficiency levels for economically disadvantaged eighth grade students in reading, math, and science assessments on the 2014 and 2017 state report card?

HO11: There is no significant difference between proficiency levels for economically disadvantaged eighth grade students in reading, math, and science assessments on the 2014 and 2017 state report card.

\section{Results}

Research Question 1: Is there a significant difference in proficiency scores for economically disadvantaged middle level students in North Carolina schools with 1-40\% poverty rates on the 2014 and 2017 standardized achievement tests?

HO1: There is no significant difference in proficiency scores for economically disadvantaged middle level students in North Carolina schools with $1-40 \%$ poverty rates on the 2014 and 2017 standardized achievement tests.

An independent-samples $t$ test was conducted to evaluate the hypothesis that economically disadvantaged North Carolina middle grades students in schools with $1-40 \%$ poverty rates achieved similar proficiency in both reading and math End of Grade Assessments in 2014 as economically disadvantaged North Carolina middle grades students in schools with $1-40 \%$ poverty rates in 2017 . The test was not significant, $\mathrm{t}(659)=0.54, \mathrm{p}=.589$, so the null hypothesis was retained. Students who were considered economically disadvantaged in schools with $1-40 \%$ poverty rates in $2014(\mathrm{M}=49.9, \mathrm{SD}=13.0)$ on average achieved similar proficiency on both reading and math standardized assessments when compared with economically disadvantaged middle grades students in schools with $1-40 \%$ poverty rates in $2017(\mathrm{M}=49.4, \mathrm{SD}=13.4)$. The $95 \%$ confidence interval for the difference in means ranged from -1.43 to 2.52 . Cohen's $d$ was 0.04 , indicating a very small effect size.

Research Question 2: Is there a significant difference in proficiency scores for economically disadvantaged middle level students in North Carolina schools with 41-60\% poverty rates on the 2014 and 2017 standardized achievement tests?

$\mathrm{HO}$ : There is no significant difference in proficiency scores for economically disadvantaged middle level students in North Carolina schools with $41-60 \%$ poverty rates on the 2014 and 2017 standardized achievement tests.

An independent-samples $t$ test was conducted to evaluate the hypothesis that economically disadvantaged North Carolina middle grades students in schools with $41-60 \%$ poverty rates achieved similar proficiency in both reading and math End of Grade Assessments in 2014 as economically disadvantaged North Carolina middle grades students in schools with $41-60 \%$ poverty rates in 2017 . The test was not significant, $\mathrm{t}(1155)=0.56 \mathrm{p}=.574$, so the null hypothesis was retained. Students who were considered economically disadvantaged in schools with $41-60 \%$ poverty rates in $2014(\mathrm{M}=43.7, \mathrm{SD}=11.2)$ on average achieved similar proficiency on both reading and math standardized assessments when compared with economically disadvantaged middle grades students in schools with $41-60 \%$ poverty rates in $2017(\mathrm{M}=43.3 \mathrm{SD}=12.1)$. The $95 \%$ confidence interval for the difference in means ranged from -.956 to 1.724 . Cohen's d was 0.03 , indicating a very small effect size.

Research Question 3: Is there a significant difference in proficiency scores for economically disadvantaged middle level students in North Carolina schools with $61-80 \%$ poverty rates on the 2014 and 2017 standardized achievement tests?

HO3: There is no significant difference in proficiency scores for economically disadvantaged middle level students in North Carolina schools with 61-80\% poverty rates on the 2014 and 2017 standardized achievement tests.

An independent-samples $t$ test was conducted to evaluate the hypothesis that economically disadvantaged North Carolina middle grades students in schools with $61-80 \%$ poverty rates achieved similar proficiency in both 
reading and math End of Grade Assessments in 2014 as economically disadvantaged North Carolina middle grades students in schools with $61-80 \%$ poverty rates in 2017 . The test was not significant, $\mathrm{t}(1197)=0.11, \mathrm{p}=.909$, so the null hypothesis was retained. Students who were considered economically disadvantaged in schools with $61-80 \%$ poverty rates in $2014(\mathrm{M}=37.0, \mathrm{SD}=11.4)$ on average achieved similar proficiency on both reading and math standardized assessments when compared with economically disadvantaged middle grades students in schools with $61-80 \%$ poverty rates in $2017(\mathrm{M}=36.9, \mathrm{SD}=12.3)$. The $95 \%$ confidence interval for the difference in means ranged from -1.26 to 1.41 . Cohen's $d$ was 0.01 , indicating a very small effect size.

Research Question 4: Is there a significant difference in proficiency scores for economically disadvantaged middle level students in North Carolina schools with $81-100 \%$ poverty rates on the 2014 and 2017 standardized achievement tests?

HO4: There is no significant difference in proficiency scores for economically disadvantaged middle level students in North Carolina schools with $81-100 \%$ poverty rates on the 2014 and 2017 standardized achievement tests.

An independent-samples $t$ test was conducted to evaluate the hypothesis that economically disadvantaged North Carolina middle grades students in schools with $81-100 \%$ poverty rates achieved similar proficiency in both reading and math End of Grade Assessments in 2014 as economically disadvantaged North Carolina middle grades students in schools with $81-100 \%$ poverty rates in 2017 . The test was not significant, $\mathrm{t}(267)=0.27, \mathrm{p}=.787$, so the null hypothesis was retained. Students who were considered economically disadvantaged in schools with $81-100 \%$ poverty rates in $2014(\mathrm{M}=27.8, \mathrm{SD}=11.2)$ on average achieved similar proficiency on both reading and math standardized assessments when compared with economically disadvantaged middle grades students in schools with $81-100 \%$ poverty rates in $2017(\mathrm{M}=27.4, \mathrm{SD}=14.7)$. The $95 \%$ confidence interval for the difference in means ranged from -2.16 to 2.84 . Cohen's $d$ was 0.03 , indicating a very small effect size.

Research Question 5: Is there a significant difference in proficiency scores for all middle level students in North Carolina schools with 1-40\% poverty rates on the 2014 and 2017 standardized achievement tests?

HO5: There is no significant difference in proficiency scores for all middle level students in North Carolina schools with $1-40 \%$ poverty rates on the 2014 and 2017 standardized achievement tests.

An independent-samples t test was conducted to evaluate the hypothesis that North Carolina middle grades students in schools with $1-40 \%$ poverty rates achieved similar proficiency in both reading and math End of Grade Assessments in 2014 as North Carolina middle grades students in schools with $1-40 \%$ poverty rates in 2017 . The test was not significant, $\mathrm{t}(682)=1.28, \mathrm{p}=.202$, so the null hypothesis was retained. Students who were enrolled in schools with $1-40 \%$ poverty rates in $2014(\mathrm{M}=70.23, \mathrm{SD}=9.92)$ on average achieved similar proficiency on both reading and math standardized assessments when compared with middle grades students enrolled in schools with $1-40 \%$ poverty rates in $2017(\mathrm{M}=69.2, \mathrm{SD}=11.2)$. The $95 \%$ confidence interval for the difference in means ranged from -.55 to 2.59 . Cohen's d was 0.10 , indicating a very small effect size.

Research Question 6: Is there a significant difference in proficiency scores for all middle level students in North Carolina schools with $41-60 \%$ poverty rates on the 2014 and 2017 standardized achievement tests?

HO6: There is no significant difference in proficiency scores for all middle level students in North Carolina schools with $41-60 \%$ poverty rates on the 2014 and 2017 standardized achievement tests.

An independent-samples $t$ test was conducted to evaluate the hypothesis that North Carolina middle grades students in schools with 41-60\% poverty rates achieved similar proficiency in both reading and math End of Grade Assessments in 2014 as North Carolina middle grades students in schools with 41-60\% poverty rates in 2017 . The test was significant, $\mathrm{t}(1170)=2.55, \mathrm{p}=.01$, so the null hypothesis was rejected. Students who were enrolled in schools with $41-60 \%$ poverty rates in $2014(\mathrm{M}=55.6, \mathrm{SD}=10.0)$ on average achieved significantly higher proficiency on both reading and math standardized assessments when compared with middle grades students enrolled in schools with $41-60 \%$ poverty rates in $2017(\mathrm{M}=53.9, \mathrm{SD}=12.6)$. The $95 \%$ confidence interval for the difference in means ranged from .39 to 2.98 . Cohen's d was 0.15 , indicating a very small effect size.

Research Question 7: Is there a significant difference in proficiency scores for all middle level students in North Carolina schools with $61-80 \%$ poverty rates on the 2014 and 2017 standardized achievement tests?

HO7: There is no significant difference in proficiency scores for all middle level students in North Carolina schools with $61-80 \%$ poverty rates on the 2014 and 2017 standardized achievement tests.

An independent-samples $t$ test was conducted to evaluate the hypothesis that North Carolina middle grades students in schools with $61-80 \%$ poverty rates achieved similar proficiency in both reading and math End of Grade 
Assessments in 2014 as North Carolina middle grades students in schools with $61-80 \%$ poverty rates in 2017 . The test was not significant, $\mathrm{t}(1203)=.63, \mathrm{p}=.53$, so the null hypothesis was retained. Students who were enrolled in schools with $61-80 \%$ poverty rates in $2014(\mathrm{M}=43.5, \mathrm{SD}=12.3)$ on average achieved similar proficiency on both reading and math standardized assessments when compared with middle grades students enrolled in schools with $61-80 \%$ poverty rates in $2017(\mathrm{M}=43.1, \mathrm{SD}=13.9$. The $95 \%$ confidence interval for the difference in means ranged from -1.0 to 1.94 . Cohen's $d$ was 0.03 , indicating a very small effect size.

Research Question 8: Is there a significant difference in proficiency scores for all middle level students in North Carolina schools with $81-100 \%$ poverty rates on the 2014 and 2017 standardized achievement tests?

HO8: There is no significant difference in proficiency scores for all middle level students in North Carolina schools with $81-100 \%$ poverty rates on the 2014 and 2017 standardized achievement tests.

An independent-samples $t$ test was conducted to evaluate the hypothesis that North Carolina middle grades students in schools with $81-100 \%$ poverty rates achieved similar proficiency in both reading and math End of Grade Assessments in 2014 as North Carolina middle grades students in schools with $81-100 \%$ poverty rates in 2017. The test was not significant, $\mathrm{t}(289)=.14, \mathrm{p}=.891$, so the null hypothesis was retained. Students who were enrolled in schools with $81-100 \%$ poverty rates in $2014(\mathrm{M}=29.5$, SD $=11.9)$ on average achieved similar proficiency on both reading and math standardized assessments when compared with middle grades students enrolled in schools with $81-100 \%$ poverty rates in $2017(\mathrm{M}=29.3, \mathrm{SD}=15.1)$. The $95 \%$ confidence interval for the difference in means ranged from -2.36 to 2.72 Cohen's $d$ was 0.01 , indicating a very small effect size.

Research Question 9: Is there a significant difference between proficiency levels for economically disadvantaged sixth grade students in both reading and math assessments on the 2014 and 2017 state report card?

HO9: There is no significant difference between proficiency levels for economically disadvantaged sixth grade students in both reading and math assessments on the 2014 and 2017 state report card.

An independent-samples $t$ test was conducted to evaluate the hypothesis that economically disadvantaged 6th grade middle grades students in North Carolina in 2014 achieved similar proficiency in both reading and math End of Grade Assessments as 6th grade economically disadvantaged middle grades students in North Carolina in 2017. The test was significant, $t(1215)=-5.39, p<.001$, so the null hypothesis was rejected. Sixth grade economically disadvantaged students in $2014(M=38.2, S D=13.0)$ on average performed significantly lower on both reading and math standardized assessments than 6th grade economically disadvantaged students in $2017(M=42.3, S D=$ 14.2). The $95 \%$ confidence interval for the difference in means ranged from -5.69 to -2.66 . Cohen's $d$ was 0.30 , indicating a small-medium effect size.

Research Question 10: Is there a significant difference between proficiency levels for economically disadvantaged seventh grade students in both reading and math assessments on the 2014 and 2017 state report card?

HO10: There is no significant difference between proficiency levels for economically disadvantaged seventh grade students in both reading and math assessments on the 2014 and 2017 state report card.

An independent-samples $t$ test was conducted to evaluate the hypothesis that economically disadvantaged 7 th grade middle grades students in North Carolina in 2014 achieved similar proficiency in both reading and math End of Grade Assessments as 7th grade economically disadvantaged middle grades students in North Carolina in 2017. The test was not significant, $t(1172)=.64, p=.524$, so the null hypothesis was retained. Seventh grade economically disadvantaged students in $2014(M=37.8, S D=13.1)$ on average achieved similar proficiency on both reading and math standardized assessments when compared with 7 th grade economically disadvantaged students in $2017(M=37.3, S D=13.8)$. The $95 \%$ confidence interval for the difference in means ranged from -1.04 to 2.04 . Cohen's $d$ was 0.04 , indicating a very small effect size.

Research Question 11: Is there a significant difference between proficiency levels for economically disadvantaged eighth grade students in reading, math, and science assessments on the 2014 and 2017 state report card?

HO11: There is no significant difference between proficiency levels for economically disadvantaged eighth grade students in reading, math, and science assessments on the 2014 and 2017 state report card.

An independent-samples $t$ test was conducted to evaluate the hypothesis that economically disadvantaged 8 th grade middle grades students in North Carolina in 2014 achieved similar proficiency in both reading and math End of Grade Assessments as 8th grade economically disadvantaged middle grades students in North Carolina in 2017. The test was not significant, $t(1202)=-1.64, p=.101$, so the null hypothesis was retained. Eighth grade economically disadvantaged students in $2014(M=41.9, S D=14.5)$ on average achieved similar proficiency on both reading and math standardized assessments when compared with 8th grade economically disadvantaged 
students in $2017(M=43.3, S D=14.0)$. The 95\% confidence interval for the difference in means ranged from -2.95 to .26 . Cohen's $d$ was 0.10 , indicating a very small effect size.

Below, Tables 1 and 2 outline the confidence intervals of pairwise differences in mean proficiency scores in North Carolina End-of-Grade achievement tests for all middle grades students in 2014 and 2017, along with areas of significant differences highlighted; these scores indicate that there continue to be significant differences between socioeconomic groups in schools with varying poverty levels, despite the completion of a full curriculum cycle with implementation of the Common Core curriculum in the 2012-2013 academic year.

Table 1. 95\% confidence intervals of pairwise differences in mean proficiency scores in North Carolina end-of-grade standardized tests of middle grades students among different levels of socioeconomic status, 2014

\begin{tabular}{lllllll}
\hline SES Level & $\mathrm{N}$ & $\mathrm{M}$ & $\mathrm{SD}$ & $1 \%-40 \%$ ED & $41 \%-60 \%$ ED & $61 \%-80 \%$ ED \\
\hline $1 \%-40 \%$ ED & 304 & 49.9 & 13.0 & - & - & - \\
$41 \%-60 \%$ ED & 537 & 43.7 & 11.2 & {$[4.50,8.00]^{*}$} & - & - \\
$61 \%-80 \%$ ED & 623 & 37.0 & 11.4 & {$[11.20,14.64]^{*}$} & {$[5.36,7.97]^{*}$} & - \\
$81 \%-100 \%$ ED & 357 & 27.8 & 11.2 & {$[20.28,24.03]^{*}$} & {$[14.40,17.40]^{*}$} & {$[7.77,10.70]^{*}$} \\
\hline
\end{tabular}

Note. *Significant at the .05 level.

Table $2.95 \%$ confidence intervals of pairwise differences in mean proficiency scores in reading and mathematics standardized tests of middle grades students among different levels of socioeconomic status, 2017

\begin{tabular}{lllllll}
\hline SES Level & $\mathrm{N}$ & $\mathrm{M}$ & $\mathrm{SD}$ & $1 \%-40 \%$ ED & $41 \%-60 \%$ ED & $61 \%-80 \%$ ED \\
\hline $1 \%-40 \%$ ED & 396 & 49.4 & 13.4 & & - & - \\
$41 \%-60 \%$ ED & 630 & 43.3 & 12.1 & {$[4.47,7.72]^{*}$} & - & - \\
$61 \%-80 \%$ ED & 596 & 36.9 & 12.3 & {$[10.81,14.10]^{*}$} & {$[4.99,7.73]^{*}$} & - \\
$81 \%-100 \%$ ED & 171 & 27.4 & 14.8 & {$[19.38,24.53]^{*}$} & {$[13.45,18.27]^{*}$} & {$[7.07,11.92]^{*}$} \\
\hline
\end{tabular}

Note. * Significant at the .05 level.

The graphs below compare student proficiency grades with different variables in North Carolina in 2014 and 2017. Figure 1 compares overall proficiency rates between all North Carolina middle grades students and economically disadvantaged middle grades students in North Carolina in 2014 and in 2017, broken into content area, grade level, and the passing rates for each grade level in both reading and mathematics. Figure 1 outlines the overall proficiency rates of all students passing math and reading standardized assessments versus economically disadvantaged (ED) students passing math and reading assessments in 2014 and 2017. Figure 2 illustrates math grades in schools with greater than $50 \%$ poverty rates (with grades determined by the North Carolina Department of Public Instruction) in 2014 and 2017. Figure 3 compares reading grades in schools with greater than 50\% poverty rates (with grades determined by the North Carolina Department of Public Instruction) in 2014 and 2017. overall school grades in schools with both less than and more than 50\% poverty rates in both 2014 and 2017. Figure 4 compares the overall school grades (with grades assigned by the North Carolina Department of Public Instruction) of schools with less than and greater than 50\% poverty rates in 2014 versus 2017. Finally, Figure 5 compares the mean proficiency scores specifically for middle level students in North Carolina from the 2011-2012, 2012-2013, 2013-2014, and 2016-2017 academic years, illustrating the progression of student scores since the end of the North Carolina Standard Course of Study through the initial implementation of Common Core and to the most recent testing data available in the state after a full curriculum cycle of Common Core. 


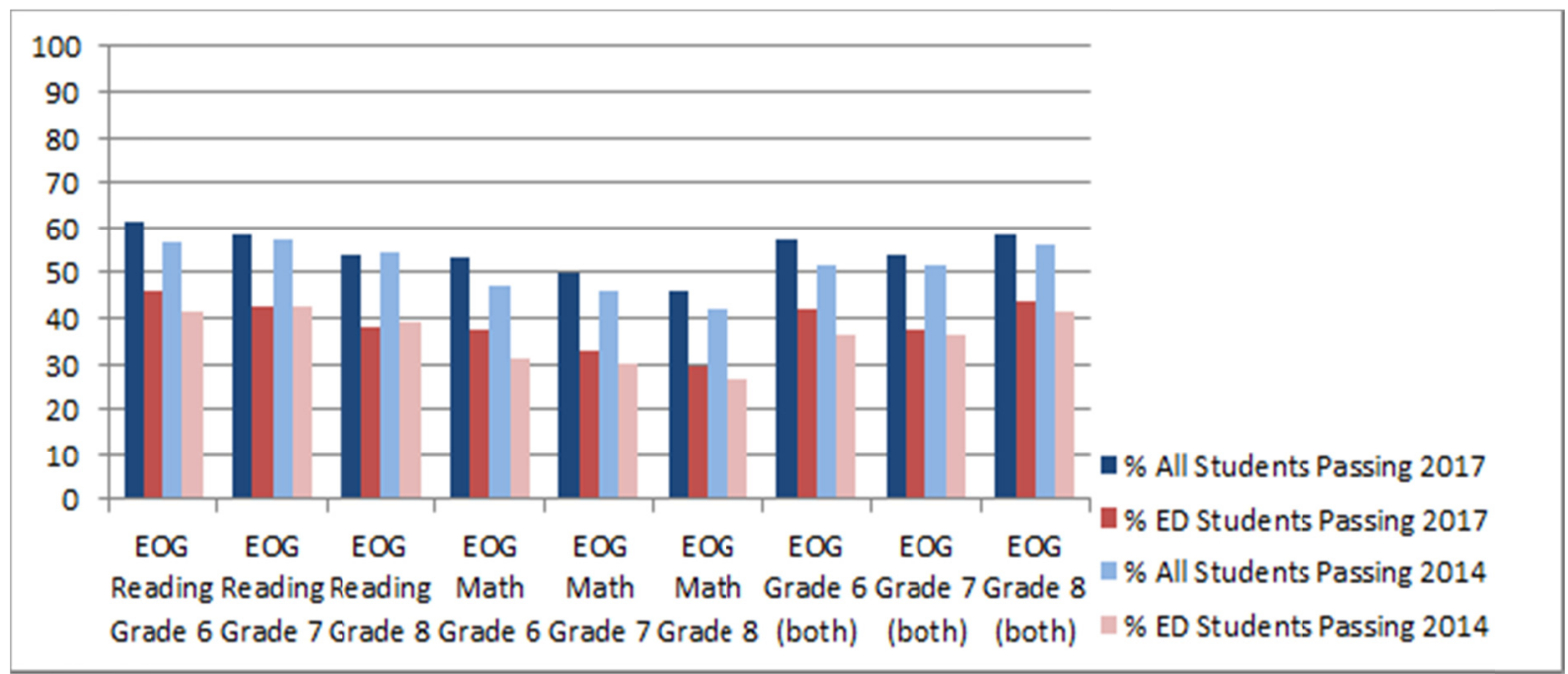

Figure 1. Comparison of overall proficiency rates with all students vs. economically disadvantaged students, 2014 vs. 2017

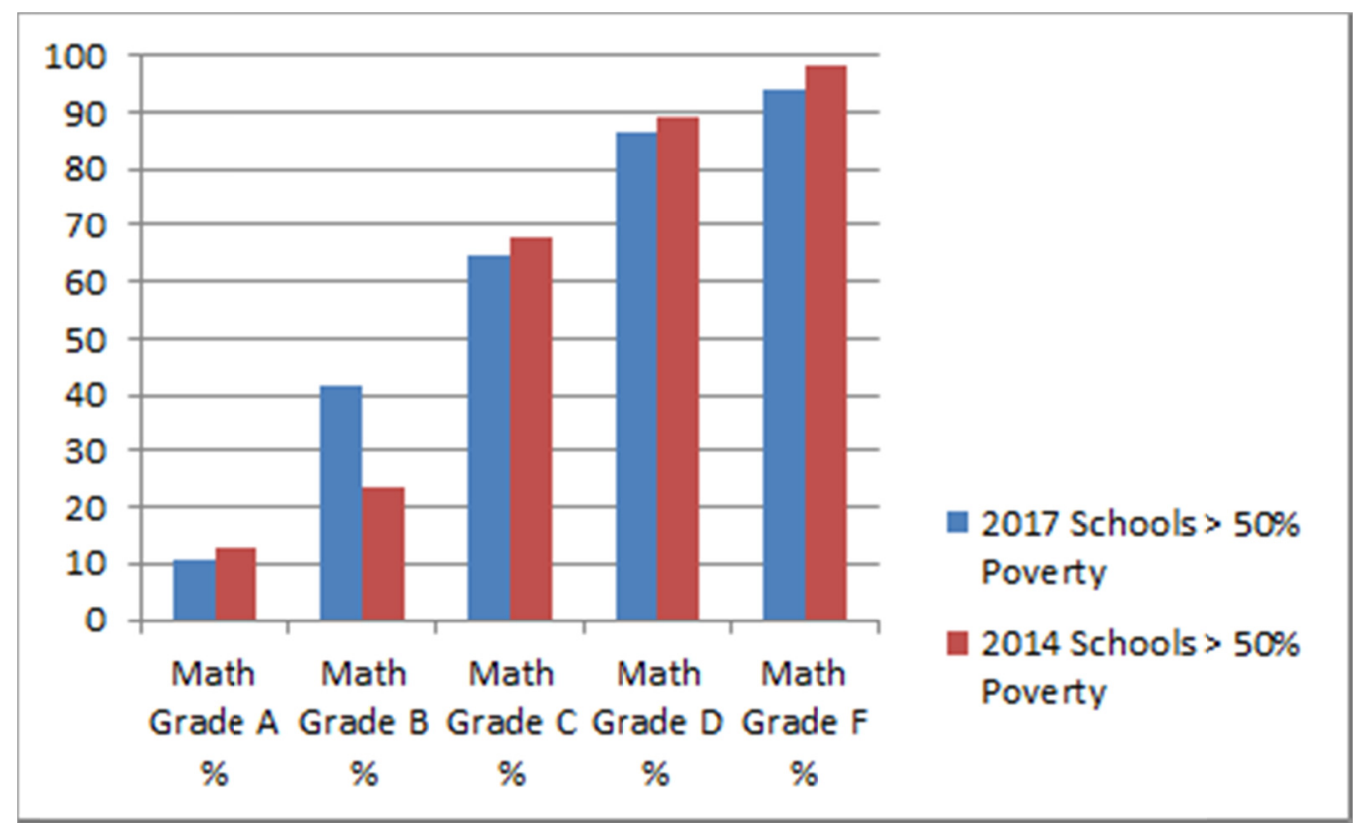

Figure 2. Comparison of math grades as assigned by the North Carolina Department of Public Instruction in schools with greater than 50\% poverty, 2014 vs. 2017 (courtesy of NC DPI) 


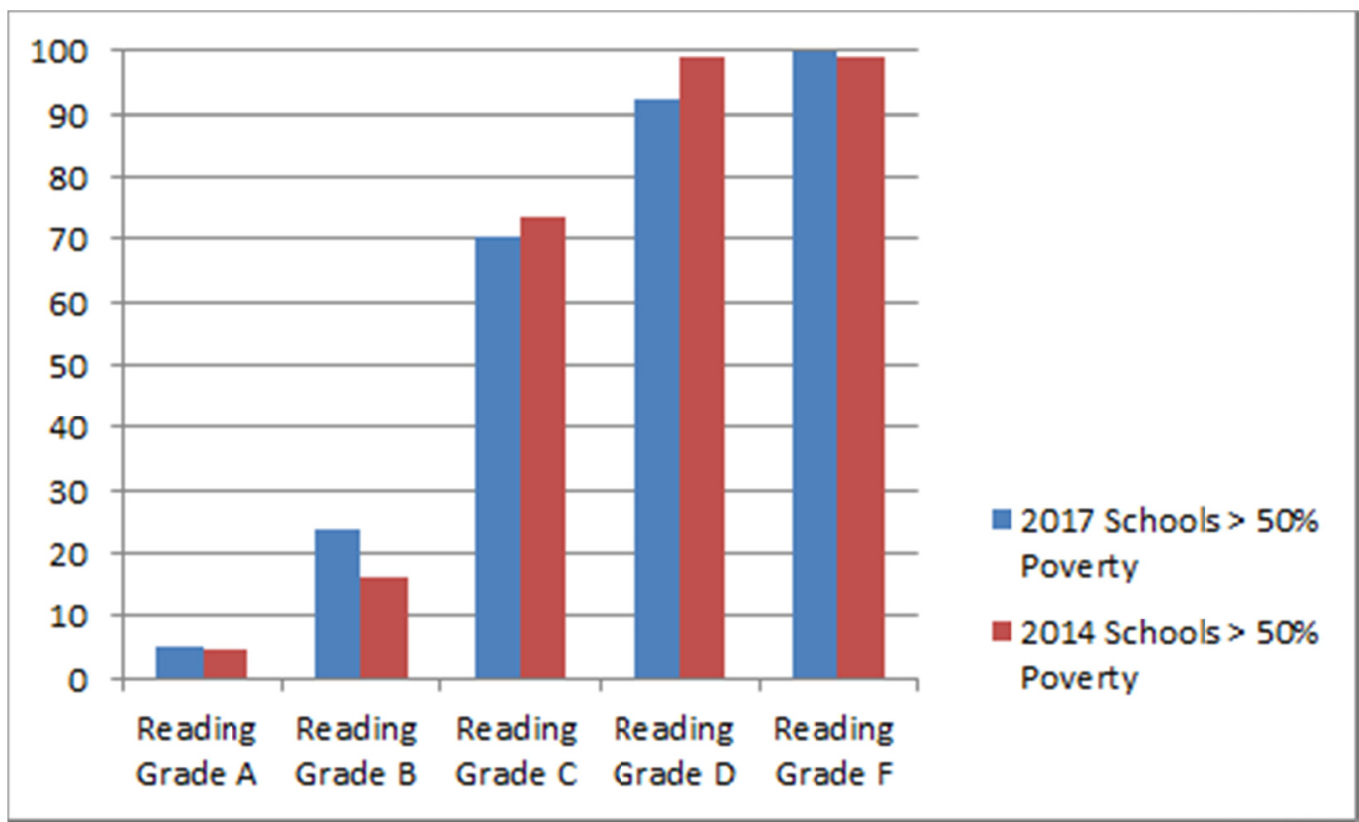

Figure 3. Comparison of reading grades as assigned by the North Carolina Department of Public Instruction in schools with greater than 50\% poverty, 2014 vs. 2017 (courtesy of NC DPI)

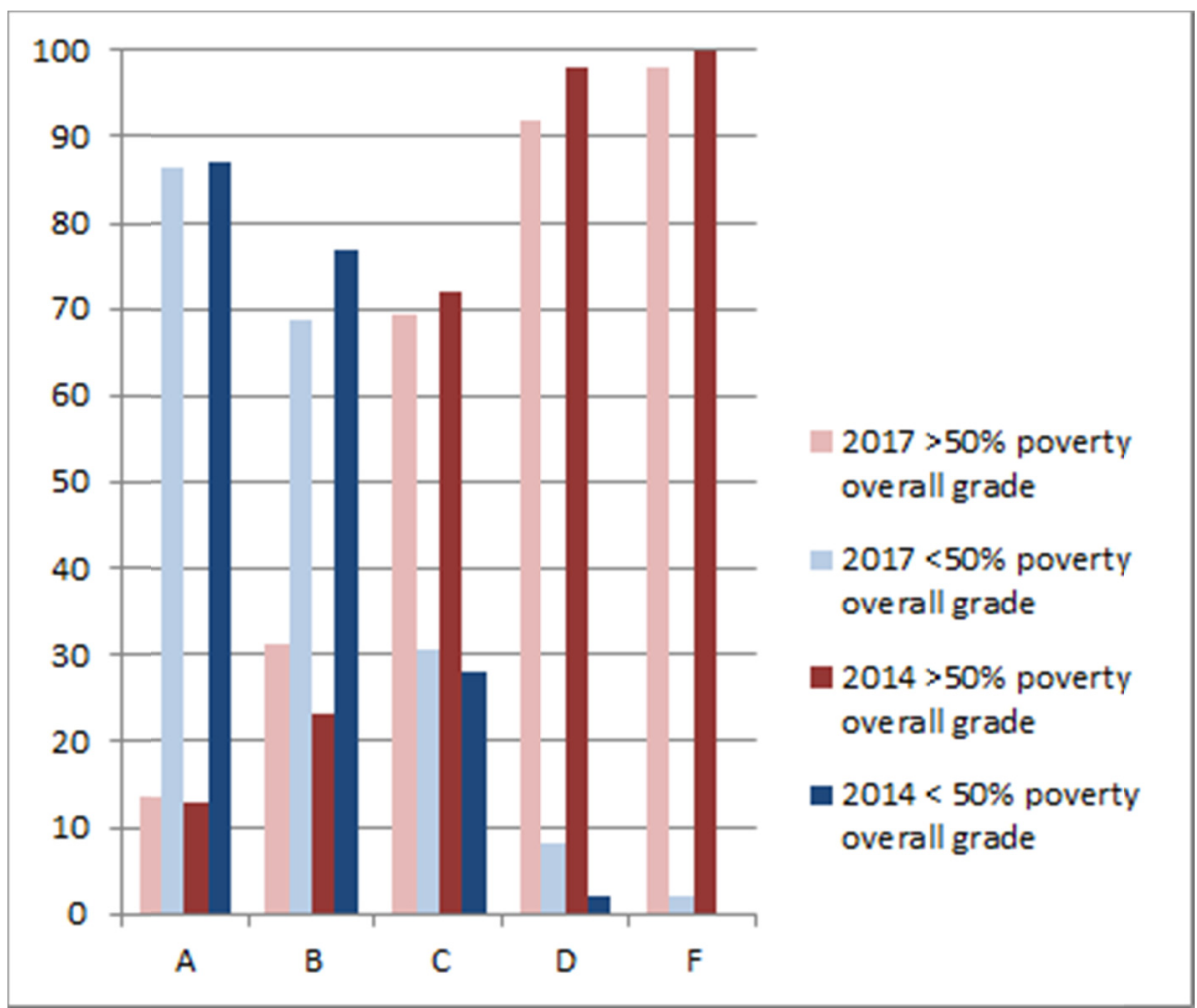

Figure 4. Comparison of overall grades as assigned by the North Carolina Department of Public Instruction in schools with less than vs. greater than 50\% poverty, 2014 vs. 2017 (courtesy of NC DPI) 


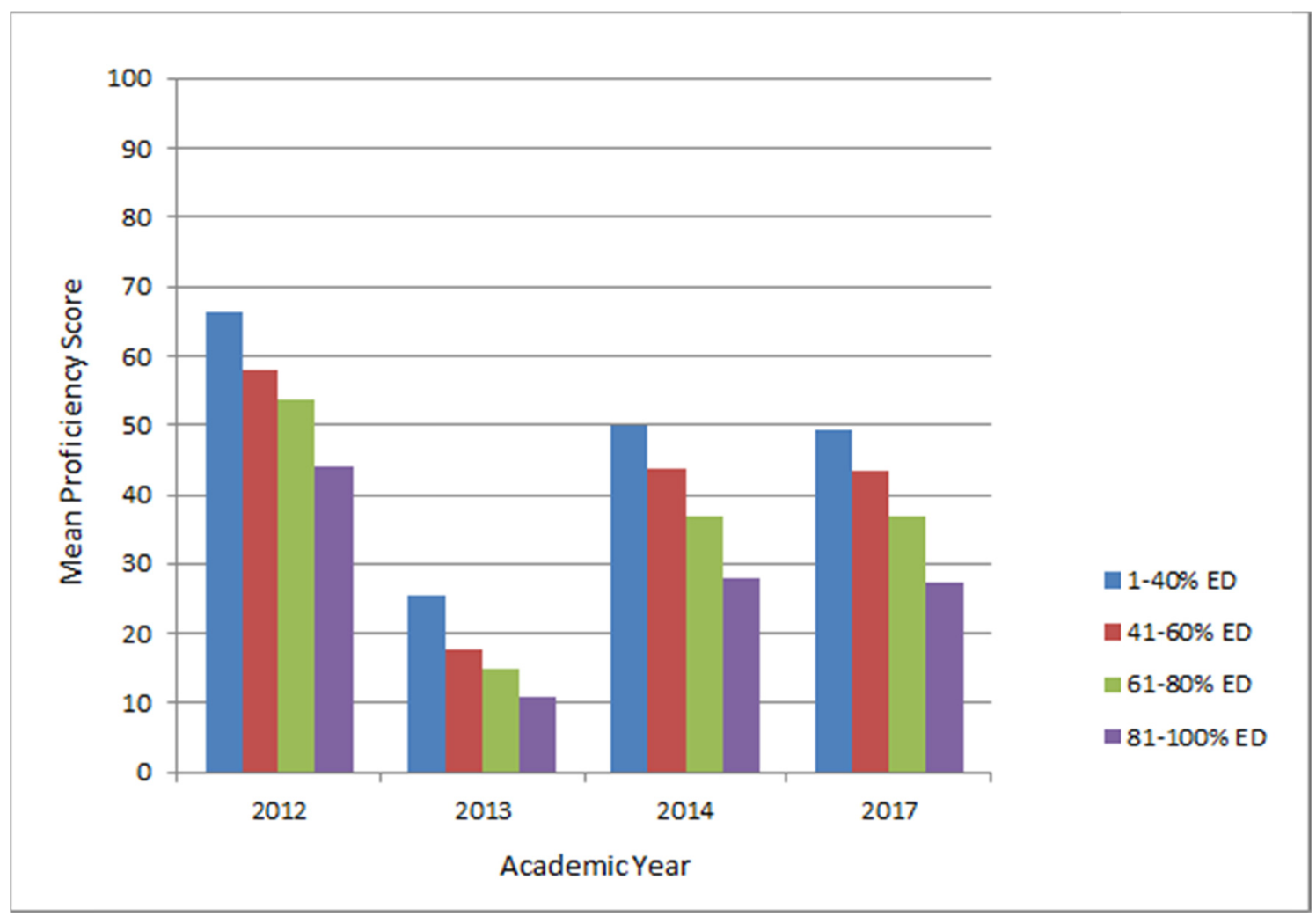

Figure 5. Comparison of mean proficiency scores of North Carolina Middle Schools within various categories of school poverty rates, 2012-2017

\section{Discussion}

Significant differences were found in proficiency levels of each grade level and in each subject area (both reading and math) in both 2014 and 2017. Schools with higher poverty levels scored significantly lower than schools in a higher income bracket. This relationship was consistently found for each socioeconomic group comparison $(1 \%-$ $40 \%$ of students on free or reduced cost lunch, $41 \%-60 \%$ of students on free or reduced cost lunch, $61 \%-80 \%$ of students on free or reduced cost lunch, and $81 \%-100 \%$ of students on free or reduced cost lunch). This suggests that there may be a negative correlation between socioeconomic status and academic achievement. The fewer students in poverty a school has the higher the academic achievement scores for that school, and the higher the poverty level in a school the lower the academic achievement; furthermore, there were no significant differences between the same socioeconomic groups when comparing 2014 and 2017 achievement scores. For instance, schools in the $61-80 \%$ socioeconomic bracket in 2014 had no statistically significant scores than schools in the $61-80 \%$ bracket in 2017. Verification of these findings would suggest that there has been little change in educational outcomes for impoverished children since the Coleman Report (1966).

Furthermore, the graphical analyses support these assertions in that there is an inverse relationship between socioeconomic status and student achievement; that is, the poorer a school is, the more poorly it is graded. The final graph also indicates that there was a significant decline in student achievement across all socioeconomic status groups in the first year of Common Core implementation (2013). Scores across all socioeconomic levels rebounded in 2014 and continued to improve in 2017, but they have not yet reached pre-Common Core proficiency levels. Additionally, the relationship between socioeconomic status and student achievement remains essentially unchanged despite the change in curriculum; the poorest students continue to underachieve compared their wealthier counterparts.

After analyzing these data, it is apparent that student socioeconomic status and academic achievement continue to be negatively correlated, supporting earlier research by Sirin (2005) and White (1982); that is, the higher the poverty level within a school, the lower the academic achievement of all students, but particularly those that are categorized as economically disadvantaged, based on end-of-grade standardized test scores. Despite the implementation of a new curriculum (Common Core) over a five-year curriculum cycle, students in high poverty schools, as well as students considered economically disadvantaged, continue to maintain an achievement gap 
when compared to their wealthier peers. As a result, educators in teacher preparation must explicitly and deliberately prepare teaching candidates for possible future placements in high poverty settings.

An informal survey of five teacher preparation programs in the Appalachian region "revealed no explicit approach to preparing teacher candidates for teaching students of poverty" and merely rely on "broad diversity statements" in course syllabi and descriptions as evidence of preparation for instruction of students in poverty (Author, 2016, p. 26). Per the recommendation of these researchers, this author sought to find exemplar teaching preparation programs that specifically address pedagogical strategies with identified assessment measures for student learning in high poverty settings; two such programs came to light after this search.

The Francis Marion Center of Excellence at Francis Marion University in Florence, South Carolina provides one model for preparing teaching candidates to excel in high poverty placements. According to the school's website, the mission of the FMU Center of Excellence to Prepare Teachers of Children of Poverty is to "increase the achievement of children of poverty by improving the quality of undergraduate teacher preparation, graduate teacher preparation, and the professional development of in-service teachers" (2017). In this program, there are six overarching, thematic standards (based on current research) for student proficiency: 1) Student life in poverty; 2) Language and literacy; 3) Family and community partnerships; 4) Classroom community; 5) Curriculum design, instructional strategies, assessment; and 6) Teachers as leaders, learners, and advocates. Each standard has detailed objectives outlining how these standards are to be addressed in the higher education classroom, along how the strategies are to be implemented in the public school setting; for example, element 5.3 under standard 5 states that teaching candidates will "apply current research to explain appropriate types of assessment methods that may be more equitable for children of or in poverty" (2017). Additionally, each semester, teaching candidates complete an attitudes and beliefs survey aligned with these program standards; these surveys are designed to gauge student perceptions of course alignment with programmatic standards as well as how they feel these standards prepare them for their future classrooms. By explicitly preparing teachers for classrooms in high poverty settings, institutions of higher education are setting teaching candidates up for success, rather than failure and burnout; as Eric Jensen states in Teaching with Poverty in Mind, "good teachers matter more than curriculum, the administration, or what students eat for breakfast" (2009, p. 4).

Additionally, Emory and Henry College in southwest Virginia has also begun to implement pedagogical strategies for students in poverty. Given the school's geographic location in a rural, high poverty area, as well as the fact that many of the program completers go on to teach in the surrounding schools, it is important to prepare teaching candidates for their future student demographics. The Neff Education Center at Emory and Henry College prepares its teaching candidates for low socioeconomic status students through deliberate field placements in high poverty settings as well as a completion of poverty and trauma-informed care modules in its Educational Psychology and Practicum Courses. Students begin field placements in the initial class in the program, and these placements continue each semester until the professional/student teaching semester; these field experiences are intentionally structured to range from a more "urban" setting in Bristol, Virginia to a very rural setting in the hills of Smyth County, north of the college. In this way, students are exposed to both rural and urban poverty school settings. In conjunction with these placements, students also concurrently take courses that support their field experiences by providing explicit instructional strategies focused on addressing the achievement gap for students in poverty. Furthermore, students' complete instructional modules to gain a sense of empathy and understanding of what students of low socioeconomic status live through daily. According to "Preparing Teachers for High-Needs Schools: A Focus on Thoughtfully Adaptive Teaching," teaching candidates "benefit from spending time in high-needs schools and with the students, parents, and other members of the community they will serve" (Darling-Hammond \& Bransford, 2005; McIntyre et al., 1996, as cited in Mascarenhas, Parsons, \& Burrowbridge, 2010). Students in the Neff Education Center are also taught the framework of trauma-informed care in the educational setting and provided textbooks and other ancillary materials that provide resources and strategies for teachers that have students with traumatic backgrounds, since poverty and trauma typically go hand-in-hand with one another; this supports the assertion by Mascarenhas, Parsons and Burrowbridge that candidates' experiences in field placements be closely tied to the student's coursework (p. 34). Through this multifaceted approach of theoretical frameworks, pedagogy, historical contexts, and practical application designed to develop partnerships with high poverty schools during field experiences, students at Emory and Henry leave with a deep sense of empathy and advocacy for at-risk, high poverty students.

Regardless of the curriculum or standardized assessments a state adopts, unfortunately, the data still proves that our students of highest economic need remain at the bottom of the barrel in terms of student achievement; the achievement gap continues to persist despite policy and curricular changes. The Common Core, like other curriculum redesign and testing strategies driving the educational reform movement, cannot by itself solve the 
problems generated by poverty (E. Glover, personal communication, 2014). This author asserts that while testing and curricula will always be mutable, there is one constant: one cannot underestimate the transformative power of a quality teacher in a child's life. Because of this, institutions of higher education must create programs that address the needs of the high poverty learner with intentionality and a solid research foundation. By explicitly addressing the unique needs of the low socioeconomic status student, teachers have a far greater chance of meeting these needs and begin the important work of closing this achievement gap; in doing so, this is the greatest way that we can promote equity in our schools. Ban Ki-Moon, however, says it best: "Education promotes equality and lifts people out of poverty. It teaches children how to become good citizens. Education is not just for a privileged few, it is for everyone. It is a fundamental human right."

\section{References}

Achievement Gap. (2004). Education Weekly. Retrieved from http://www.edweek.org/ew/issues/achievement-gap

Brooks-Gunn, J., Duncan, G., \& Maritato, N. (1997). Poor families, poor outcomes: The Wellbeing of children and youth. The Consequences of Growing Up Poor. New York, NY: Russell Sage Foundation.

Brown, G., \& Hattie, J. (2012). The benefits of regular standardized assessment in childhood education: Guiding improved instruction learning. Retrieved from https://www.academia.edu/1964802/The_benefits_of_regular_standardized_assessment_in_childhood_educ ation_Guiding_improved_instruction_and_learning

Coleman, J. (1966). Equality of educational opportunity. National Center for Educational Statistics. Retrieved from https://files.eric.ed.gov/fulltext/ED012275.pdf

Dotson, L., \& Foley, V. (2016). Middle grades student achievement and poverty levels: Implications for teacher preparation. Journal of Learning in Higher Education, 12(2), 33-44.

Horn, C. (2003). High-stakes testing and students: Stopping or perpetuating a cycle of failure? Theory into Practice, 42(1), 30-41. https://doi.org/10.1353/tip.2003.0009

Jensen, E. (2009). Teaching with poverty in mind: What being poor does to kids'brains and what schools can do about it. Alexandria, VA: Association for Supervision and Curriculum Development.

Kennedy, B. (2016). More than 20 percent of north carolina children attend a high-poverty school. North Carolina Justice Center. Retrieved September 20, 2019, from https://www.ncjustice.org/publications/more-than-20-percent-of-nc-student.s-attend-a-high-poverty-school/

Mascarenhas, A., Parsons, S., \& Burrowbridge, S. (2010). Preparing teachers for high-needs schools: A Focus on thoughtfully adaptive teaching. Bank Street College of Education Occasional Paper Series, 25(1), 28-43. Retrieved from https://files.eric.ed.gov/fulltext/ED521599.pdf

McNeil, M. (2011). Duncan: 82 percent of schools could be failing this year. Education Week. Retrieved from http://blogs.edweek.org/edweek/campaign-k-12/2011/03/duncan_82_of_schools_could_be.html

Morgan, P., Farkas, G., Hillemeier, M., \& Maczuga, S. (2009). Risk factors for learning-related behavior problems at 24 months of age: Population-based estimates. Journal of Abnormal Child Psychology, 37, 401-413. https://doi.org/10.1007/s10802-008-9279-8

National Equity Atlas. (2018). School poverty: North Carolina. The National Equity Atlas. Retrieved September 20, 2019, from https://nationalequityatlas.org/indicators/School_poverty/Over_time\%3A35536/North_Carolina/false/Schoo 1_type\%3AAll_public_schools

Neuman, S. (2013). The American dream: Slipping away? Faces of Poverty, 70(8), 18-22.

NKA. (2006). Teacher retention at low performing schools. Using the Evidence. Retrieved from https://childandfamilypolicy.duke.edu/pdfs/pubpres/Research_Update_Dec06.pdf

NKA. (2017). Standards for teachers of children of poverty. Francis Marion University Center of Excellence to Prepare Teachers for Children of Poverty. Retrieved from https://www.fmucenterofexcellence.org/courses-and-certifications/standards-for-teachers-of-children-of-pov erty

Ohanian, S. (2002). Collateral vomitage. $\quad$ Retrieved from http://www.sacbee.com/content/news/education/story/1852977p-1949391c.html

Palardy, G. (2008). Differential school effects among low, middle, and high social class composition schools: A 
multiple group, multilevel latent growth curve analysis. School Effectiveness and School Improvement, 19, 21-49. https://doi.org/10.1080/09243450801936845

Pawloski, T. (2014, March). From F to A: Impact of leadership and sustained professional development in high-poverty schools. Speech presented at North Carolina Association for School Administrators Conference, Raleigh, NC.

Popham, J. (2001). Introduction: How we arrived at this unhappy place. Truth About Testing. Retrieved from http://www.ascd.org/publications/books/101030/chapters/Introduction@-How-WeArrived-at-This-Unhappy -Place.aspx

Sirin, S. (2005). Socioeconomic status and academic achievement: A meta-analytic review of research. Review of Educational Research, 75(3), 417-453. https://doi.org/10.3102/00346543075003417

Tavernise, S. (2012). Education gap grows between rich and poor, studies say. The New York Times: Education. Retrieved from http://www.nytimes.com/2012/02/10/education/education-gap-grows-between-rich-andpoor-studies-show.ht $\mathrm{ml}$ ?pagewanted=all\&_r=0

White, K. R. (1982). The relation between socioeconomic status and academic achievement. Psychological Bulletin, 91(3), 461-481. https://doi.org/10.1037//0033-2909.91.3.461

White, S. B., Reynolds, P. D., Thomas, M. M., \& Gitzlaff, N. J. (1993). Socioeconomic status and achievement revisited. Urban Education, 28(3), 328-343. https://doi.org/10.1177/0042085993028003007

\section{Copyrights}

Copyright for this article is retained by the author, with first publication rights granted to the journal.

This is an open-access article distributed under the terms and conditions of the Creative Commons Attribution license (http://creativecommons.org/licenses/by/4.0/). 